\title{
Association between Toxoplasma gondii Exposure and Suicidal Behavior in Patients Attending Primary Health Care Clinics
}

\author{
Cosme Alvarado-Esquivel 1,*Did, Sergio Estrada-Martínez ${ }^{2}$, Agar Ramos-Nevárez ${ }^{3}$, Alma Rosa Pérez-Álamos ${ }^{2}$, \\ Isabel Beristain-García ${ }^{4}$, Ángel Osvaldo Alvarado-Félix ${ }^{1}$, Sandra Margarita Cerrillo-Soto ${ }^{3}$, \\ Antonio Sifuentes-Álvarez ${ }^{1}$, Gustavo Alexis Alvarado-Félix ${ }^{1}$, Carlos Alberto Guido-Arreola ${ }^{3}$ \\ and Leandro Saenz-Soto ${ }^{3}$
}

1 Biomedical Research Laboratory, Faculty of Medicine and Nutrition, Juárez University of Durango State, Avenida Universidad S/N, Durango 34000, Mexico; aoafangel@hotmail.com (A.O.A.-F.); sifual55@hotmail.com (A.S.-A.); gaafalexis15@gmail.com (G.A.A.-F.)

2 Institute for Scientific Research "Dr. Roberto Rivera-Damm", Juárez University of Durango State, Avenida Universidad S/N, Durango 34000, Mexico; semdurango@hotmail.com (S.E.-M.); almaross1@yahoo.es (A.R.P.-A.)

3 Clínica de Medicina Familiar, Instituto de Seguridad y Servicios Sociales de los Trabajadores del Estado, Predio Canoas S/N, Durango 34079, Mexico; agar_ramos@hotmail.com (A.R.-N.);

check for

updates

Citation: Alvarado-Esquivel, C.; Estrada-Martínez, S.; Ramos-Nevárez, A.; Pérez-Álamos, A.R.;

Beristain-García, I.; Alvarado-Félix, Á.O.; Cerrillo-Soto, S.M.; Sifuentes-Álvarez, A.; Alvarado-Félix, G.A.; Guido-Arreola, C.A.; et al. Association between Toxoplasma gondii Exposure and Suicidal Behavior in Patients Attending Primary Health Care Clinics. Pathogens 2021, 10, 677. https://doi.org/10,3390/ pathogens 10060677

Academic Editor: Jaroslav Flegr

Received: 22 April 2021

Accepted: 27 May 2021

Published: 30 May 2021

Publisher's Note: MDPI stays neutral with regard to jurisdictional claims in published maps and institutional affiliations.

Copyright: (c) 2021 by the authors. Licensee MDPI, Basel, Switzerland. This article is an open access article distributed under the terms and conditions of the Creative Commons Attribution (CC BY) license (https:/ / creativecommons.org/licenses/by/ $4.0 /)$. agar.ramos@issste.gob.mx (S.M.C.-S.); cguido@issste.gob.mx (C.A.G.-A.); quim_saenz@hotmail.com (L.S.-S.)

4 Facultad de Enfermería y Obstetricia, Juárez University of Durango State, Blvd. Juan Pablo II 512, Durango 34000, Mexico; beristaingarcia@yahoo.com.mx

* Correspondence: alvaradocosme@yahoo.com; Tel.: +52-618-2364146

Abstract: This study aimed to determine the association between suicidal behavior and T. gondii seroreactivity in 2045 patients attending primary care clinics. IgG antibodies against $T$. gondii were found in 37 (12.1\%) out of 306 individuals with a history of suicidal ideation and in $134(7.7 \%)$ of 1739 individuals without this history (OR: $1.64 ; 95 \%$ CI: $1.11-2.42 ; p=0.01$ ). Seropositivity to $T$. gondii was associated with suicidal ideation in women (OR: 1.56; 95\% CI: 1.01-2.42; $p=0.03$ ) and individuals aged $\leq 30$ years (OR: 3.25; 95\% CI: $1.53-6.88 ; p=0.001$ ). No association between the rates of high ( $>150 \mathrm{IU} / \mathrm{mL}$ ) levels of anti-T. gondii IgG antibodies and suicidal ideation or suicide attempts was found. IgG antibodies against T. gondii were found in 22 of $185(11.9 \%)$ individuals with a history of suicide attempts and in $149(8.0 \%)$ of 1860 individuals without this history (OR: 1.54; 95\% CI: $0.96-2.49 ; p=0.06)$. The seroprevalence of $T$. gondii infection was associated with suicide attempts in individuals aged $31-50$ years (OR: $2.01 ; 95 \%$ CI: $1.09-3.71 ; p=0.02$ ), and with more than three suicide attempts (OR: 4.02; 95\% CI: 1.34-12.03; $p=0.008$ ). Our results indicate that $T$. gondii exposure is associated with suicidal behavior among patients attending primary care clinics.

Keywords: suicidal behavior; cross-sectional study; primary care; seroprevalence; epidemiology

\section{Introduction}

The coccidian protozoan Toxoplasma gondii (T. gondii) infects more than 100 species of vertebrates, including one-third of the human population [1,2]. Toxoplasmosis, the disease that is caused by T. gondii, is a zoonotic disease of global distribution and importance [3]. Cats are the most important host in the epidemiology of toxoplasmosis because they are the only species that can excrete oocysts in feces [4]. The main routes of transmission are by ingestion of tissue cysts in raw or undercooked meat of infected animals, ingestion of raw vegetables or water contaminated with T. gondii oocysts from cat feces, and transplacental [3]. Infection with T. gondii in an immunocompetent host does not typically show symptoms, and parasites are retained in latent tissue cysts that can be reactivated upon immune suppression and could damage key organ systems [2]. Some patients with toxoplasmosis present cervical lymphadenopathy or ocular disease [5]. Toxoplasmosis can be fatal to the fetus and immunocompromised adults [3]. The reactivation of 
latent disease in immunocompromised patients can cause life-threatening encephalitis [5]. In addition, toxoplasmosis has been linked to a range of behavioral alterations and conditions [1]. T. gondii has a preference for invading neurons and affecting the functioning of glial cells [6]. The seropositivity to $T$. gondii has been associated with mixed anxiety and depressive disorder [7], schizophrenia [8-10], obsessive-compulsive disorder [11,12], and an increased risk of traffic accidents [13]. In a study of decedents in Poland, the researchers found a strong correlation between latent $T$. gondii infection and engaging in risky behaviors leading to death [14]. Furthermore, suicide behavior in psychiatric patients has been associated with high titers of anti-T. gondii antibodies $[15,16]$ and the seroprevalence of T. gondii infection [17]. To the best of our knowledge, the link between T. gondii infection and suicide behavior in patients of primary care has not been studied. The aim of this study was to determine the association between suicidal behavior and T. gondii infection in outpatients that were attending primary health care clinics in Durango, Mexico.

\section{Results}

Out of the 2045 individuals studied, $306(15.0 \%)$ had a history of suicidal ideation and $1739(85.0 \%)$ did not have this history. IgG antibodies against $T$. gondii were found in 37 $(12.1 \%)$ of the 306 individuals with a history of suicidal ideation and in $134(7.7 \%)$ of the 1739 individuals without this history (OR: $1.64 ; 95 \%$ CI: 1.11-2.42; $p=0.01$ ). Table 1 shows a stratification by age and sex and seroprevalence of $T$. gondii infection in individuals with and without a history of suicidal ideation. Women with a history of suicidal ideation had a significantly higher (29/251: $11.6 \%$ ) seroprevalence of $T$. gondii infection than women without this history (111/1445: 7.7\%) (OR: 1.56 ; 95\% CI: 1.01-2.42; $p=0.03)$. Individuals that were aged $\leq 30$ years with a history of suicidal ideation had a significantly higher seroprevalence of $T$. gondii infection than those of the same age group without suicidal ideation (13/87: $14.9 \%$ vs 19/371: $5.1 \%$, respectively) (OR: $3.25 ; 95 \%$ CI: $1.53-6.88 ; p=0.001$ ).

High $(>150 \mathrm{IU} / \mathrm{mL}$ ) levels of anti-T. gondii IgG antibodies were found in $15(4.9 \%)$ of the 306 individuals with a history of suicidal ideation and in $50(2.9 \%)$ of the 1739 individuals without this history (OR: 1.74; 95\% CI: 0.96-3.14; $p=0.06$ ). Table 2 shows a stratification by sex and age groups and the association between high $(>150 \mathrm{IU} / \mathrm{mL})$ anti-T. gondii IgG antibody levels and suicidal ideation. A borderline association between high levels of anti-T. gondii IgG antibodies and suicidal ideation in individuals that were aged $\leq 30$ years was found (OR: 3.17 ; 95\% CI: $0.98-10.24 ; p=0.05$ ).

Anti-T. gondii IgM antibodies were found in $10(27.0 \%)$ of the 37 individuals with anti-T. gondii IgG antibodies and a history of suicidal ideation and in $26(19.4 \%)$ of the 134 individuals with anti-T. gondii antibodies without this history (OR: 1.53; 95\% CI: 0.663.57; $p=0.31$ ).

With respect to suicide attempts, of the 2045 individuals that were studied, $185(9.0 \%)$ had a history of suicide attempts and $1860(91.0 \%)$ did not have this history. IgG antibodies against $T$. gondii were found in 22 of the $185(11.9 \%)$ individuals with a history of suicide attempts and in $149(8.0 \%)$ of the 1860 individuals without this history (OR: 1.54; 95\% CI: $0.96-2.49 ; p=0.06)$. Table 3 shows a stratification by age and sex and the seroprevalence of $T$. gondii infection in individuals with and without a history of suicide attempts. Stratification by sex showed no association between T. gondii infection and suicide attempts. Whereas stratification by age groups showed that individuals aged 31-50 years with a history of suicide attempts had a significantly higher (14/89: 15.7\%) seroprevalence of T. gondii infection than individuals of the same age group without a history of suicide attempts (89/1050: 8.5\%) (OR: 2.01; 95\% CI: 1.09-3.71; $p=0.02$ ). 
Table 1. Association between T. gondii exposure and suicidal ideation, a stratification by sex and age groups.

\begin{tabular}{|c|c|c|c|c|c|c|c|c|c|}
\hline \multirow[b]{3}{*}{ Characteristic } & \multirow{2}{*}{\multicolumn{3}{|c|}{ Suicidal Ideation }} & \multicolumn{3}{|c|}{ No Suicidal Ideation } & \multirow{2}{*}{\multicolumn{3}{|c|}{$95 \%$}} \\
\hline & \multirow{2}{*}{$\begin{array}{l}\text { No. } \\
\text { Tested }\end{array}$} & & $\begin{array}{l}\text { Seropositivity } \\
\text { to T. gondii }\end{array}$ & \multirow{2}{*}{$\begin{array}{c}\text { No. } \\
\text { Tested }\end{array}$} & \multicolumn{2}{|c|}{$\begin{array}{c}\text { Seropositivity } \\
\text { to T. gondii }\end{array}$} & & & \\
\hline & & No. & $\%$ & & No. & $\%$ & OR & $\begin{array}{c}\text { Confidence } \\
\text { Interval }\end{array}$ & $\begin{array}{c}p \\
\text { Value }\end{array}$ \\
\hline \multicolumn{10}{|l|}{ Sex } \\
\hline Male & 55 & 8 & 14.5 & 294 & 23 & 7.8 & 2.00 & $0.84-4.74$ & 0.10 \\
\hline Female & 251 & 29 & 11.6 & 1445 & 111 & 7.7 & 1.56 & $1.01-2.42$ & 0.03 \\
\hline Age (years) & & & & & & & & & \\
\hline$\leq 30$ & 87 & 13 & 14.9 & 371 & 19 & 5.1 & 3.25 & $1.53-6.88$ & 0.001 \\
\hline $3 \overline{1}-50$ & 166 & 18 & 10.8 & 973 & 85 & 8.7 & 1.27 & $0.74-2.17$ & 0.38 \\
\hline$>50$ & 53 & 6 & 11.3 & 395 & 30 & 7.6 & 1.55 & $0.61-3.92$ & 0.34 \\
\hline All & 306 & 37 & 12.1 & 1739 & 134 & 7.7 & 1.64 & $1.11-2.42$ & 0.01 \\
\hline
\end{tabular}

Table 2. Association between high (>150 IU / mL) levels of anti-T. gondii IgG. antibodies and suicidal ideation, a stratification by sex and age groups.

\begin{tabular}{|c|c|c|c|c|c|c|c|c|c|}
\hline \multirow{3}{*}{ Characteristic } & \multicolumn{3}{|c|}{ Suicidal Ideation } & \multicolumn{3}{|c|}{ No Suicidal Ideation } & \multirow{3}{*}{\multicolumn{2}{|c|}{$\begin{array}{c}95 \% \\
\text { Confidence }\end{array}$}} & \multirow{3}{*}{$\begin{array}{c}p \\
\text { Value }\end{array}$} \\
\hline & \multirow{2}{*}{$\begin{array}{l}\text { No. } \\
\text { Tested }\end{array}$} & \multirow{2}{*}{\multicolumn{2}{|c|}{$>150 \mathrm{IU} / \mathrm{mL}$}} & \multirow{2}{*}{$\begin{array}{l}\text { No. } \\
\text { Tested }\end{array}$} & \multirow{2}{*}{\multicolumn{2}{|c|}{$\begin{array}{l}>150 \mathrm{IU} / \mathrm{mL} \\
\text { of IgG }\end{array}$}} & & & \\
\hline & & & & & & & & & \\
\hline Sex & & & & & & & & & \\
\hline Male & 55 & 2 & 3.6 & 294 & 6 & 2.0 & 1.81 & $0.35-9.21$ & 0.61 \\
\hline Female & 251 & 13 & 5.2 & 1445 & 44 & 3.0 & 1.73 & $0.92-3.27$ & 0.08 \\
\hline Age (years) & & & & & & & & & \\
\hline$\leq 30$ & 87 & 5 & 5.7 & 371 & 7 & 1.9 & 3.17 & $0.98-10.24$ & 0.05 \\
\hline $31-50$ & 166 & 6 & 3.6 & 973 & 33 & 3.4 & 1.06 & $0.44-2.59$ & 0.88 \\
\hline$>50$ & 53 & 4 & 7.5 & 395 & 10 & 2.5 & 3.14 & $0.94-10.40$ & 0.07 \\
\hline All & 306 & 15 & 4.9 & 1739 & 50 & 2.9 & 1.74 & $0.96-3.14$ & 0.06 \\
\hline
\end{tabular}

Table 3. The association between T. gondii exposure and suicide attempts, a stratification by sex and age groups.

\begin{tabular}{|c|c|c|c|c|c|c|c|c|c|}
\hline \multirow[b]{3}{*}{ Characteristic } & \multicolumn{3}{|c|}{ Suicide Attempts } & \multicolumn{3}{|c|}{ No Suicide Attempts } & \multirow{2}{*}{\multicolumn{2}{|c|}{$\begin{array}{c}95 \% \\
\text { Confidence }\end{array}$}} & \multirow{3}{*}{$\begin{array}{c}p \\
\text { Value }\end{array}$} \\
\hline & \multirow{2}{*}{$\begin{array}{l}\text { No. } \\
\text { Tested }\end{array}$} & \multicolumn{2}{|c|}{$\begin{array}{c}\text { Seropositivity } \\
\text { to } T \text {. gondii }\end{array}$} & \multirow{2}{*}{$\begin{array}{l}\text { No. } \\
\text { Tested }\end{array}$} & \multicolumn{2}{|c|}{$\begin{array}{c}\text { Seropositivity } \\
\text { to T. gondii }\end{array}$} & & & \\
\hline & & No. & $\%$ & & No. & $\%$ & OR & Interval & \\
\hline Sex & & & & & & & & & \\
\hline Male & 36 & 5 & 13.9 & 313 & 26 & 8.3 & 1.78 & $0.63-4.96$ & 0.34 \\
\hline Female & 149 & 17 & 11.4 & 1547 & 123 & 8.0 & 1.49 & $0.87-2.55$ & 0.14 \\
\hline Age (years) & & & & & & & & & \\
\hline$\leq 30$ & 64 & 6 & 9.4 & 394 & 26 & 6.6 & 1.46 & $0.57-3.71$ & 0.41 \\
\hline $31-50$ & 89 & 14 & 15.7 & 1050 & 89 & 8.5 & 2.01 & $1.09-3.71$ & 0.02 \\
\hline$>50$ & 32 & 2 & 6.2 & 416 & 34 & 8.2 & 0.74 & $0.17-3.26$ & 1.00 \\
\hline All & 185 & 22 & 11.9 & 1860 & 149 & 8.0 & 1.54 & $0.96-2.49$ & 0.06 \\
\hline
\end{tabular}


High (>150 IU/mL) levels of anti-T. gondii IgG antibodies were found in nine (4.9\%) of the 185 individuals with a history of suicide attempts and $56(3.0 \%)$ of the 1860 individuals without this history (OR: $1.64 ; 95 \%$ CI: 0.80-3.38; $p=0.17$ ). Table 4 shows a stratification by sex and age groups and the association between high $(>150 \mathrm{IU} / \mathrm{mL})$ anti-T. gondii IgG antibody levels and a history of suicide attempts. No association between the rates of high levels of anti-T. gondii antibodies and a history of suicide attempts among sex and age groups was found.

Anti-T. gondii IgM antibodies were found in eight (36.4\%) of the 22 individuals with anti-T. gondii IgG antibodies and a history of suicide attempts and in $28(18.8 \%)$ of the 149 individuals with anti-T. gondii antibodies without a history of suicide attempts (OR: 2.46; 95\% CI: $0.94-6.45 ; p=0.05)$. Table 5 shows a stratification by age and sex and seropositivity to anti-T. gondii IgM antibodies in the participants with anti-T. gondii IgG antibodies with and without a history of suicide attempts.

Individuals with a history of suicide attempts have attempted suicide from one to 20 (median 1) times. Individuals with more than three suicide attempts had a significantly higher seroprevalence of T. gondii infection than those with 1-3 suicide attempts (6/20: $30.0 \%$ vs 15/156: 9.6\%, respectively) (OR: 4.02; 95\% CI: $1.34-12.03 ; p=0.008$ ). The frequency of high anti-T. gondii IgG antibodies in individuals with more than three suicide attempts was similar to that found in individuals with 1-3 suicide attempts (2/20: $10.0 \%$ vs 6/156: $3.8 \%$, respectively) (OR: 2.77; 95\% CI: 0.52-14.80; $p=0.22$ ). The date (years before the interview) of the last suicide attempt was not associated with the seroprevalence of T. gondii infection $(p=0.76)$, high levels of anti-T. gondii IgG antibodies $(p=1.00)$, or anti-T. gondii IgM antibodies $(p=0.21)$. The methods of suicide attempts (wounding, hanging, drug overdose, poisoning, firearm, electrocution, fasting, or throwing themselves to vehicles) were not associated with the seroprevalence of T. gondii infection $(p=0.53)$, high levels of anti-T. gondii IgG antibodies $(p=0.50)$, or anti-T. gondii $\operatorname{IgM}$ antibodies $(p=0.33)$. 
Table 4. Association between high ( $>150 \mathrm{IU} / \mathrm{mL}$ ) levels of anti-T. gondii IgG antibodies and suicide attempts, a stratification by sex and age groups.

\begin{tabular}{|c|c|c|c|c|c|c|c|c|c|}
\hline \multirow[b]{3}{*}{ Characteristic } & \multirow{2}{*}{\multicolumn{3}{|c|}{$\begin{array}{l}\text { Suicide Attempts } \\
\qquad \begin{array}{c}>150 \mathrm{IU} / \mathrm{mL} \\
\text { of IgG }\end{array}\end{array}$}} & \multirow{2}{*}{\multicolumn{3}{|c|}{$\begin{array}{c}\text { No Suicide Attempts } \\
\qquad \begin{array}{c}>150 \mathrm{IU} / \mathrm{mL} \\
\text { of IgG }\end{array}\end{array}$}} & \multirow{3}{*}{\multicolumn{2}{|c|}{$\begin{array}{l}95 \% \\
\text { Confidence } \\
\text { Interval }\end{array}$}} & \multirow{3}{*}{$\begin{array}{c}p \\
\text { Value }\end{array}$} \\
\hline & & & & & & & & & \\
\hline & Tested & No. & $\%$ & Tested & No. & $\%$ & & & \\
\hline Male & 36 & 1 & 2.8 & 313 & 7 & 2.2 & 1.24 & $0.14-10.45$ & 0.58 \\
\hline Female & 149 & 8 & 5.4 & 1547 & 49 & 3.2 & 1.73 & $0.80-3.73$ & 0.15 \\
\hline \multicolumn{10}{|l|}{ Age (years) } \\
\hline$\leq 30$ & 64 & 3 & 4.7 & 394 & 9 & 2.3 & 2.10 & $0.55-7.98$ & 0.22 \\
\hline$>50$ & 32 & 1 & 3.1 & 416 & 13 & 3.1 & 1.00 & $0.12-7.89$ & 1.00 \\
\hline All & 185 & 9 & 4.9 & 1860 & 56 & 3.0 & 1.64 & $0.80-3.38$ & 0.17 \\
\hline
\end{tabular}

Table 5. Association between T. gondii IgM seropositivity in participants with anti- T. gondii IgG antibodies and suicide attempts, a stratification by sex and age groups.

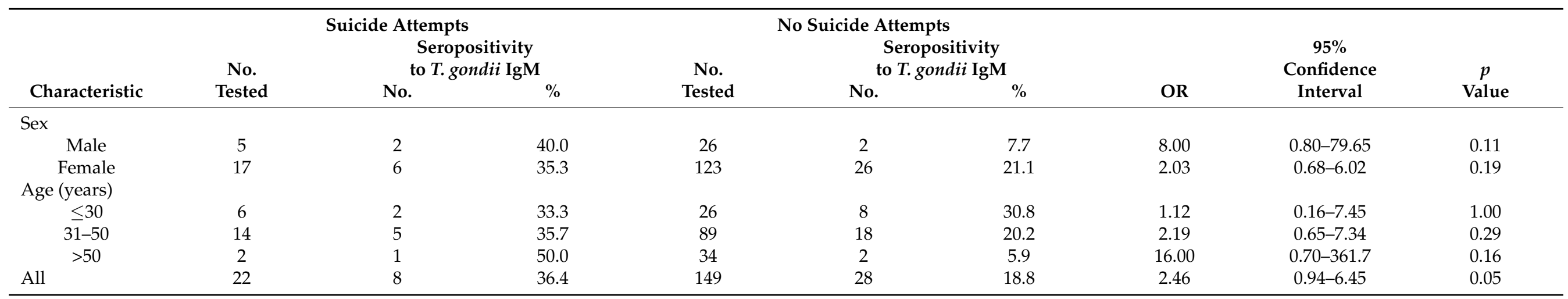




\section{Discussion}

Most of the people (91.7\%) who commit suicide had a health care contact with an emergency room visit, primary care, or outpatient specialty setting within a year prior to suicide [18]. Thus, it is important to study suicide behavior in these settings. In this study, we sought to determine the association between suicide behavior and T. gondii exposure in outpatients attending primary health care clinics. We found that the seroprevalence of T. gondii infection was significantly higher in individuals with a history of suicidal ideation than in those without this history. Therefore, the results suggest that infection with $T$. gondii is associated with suicidal ideation in patients attending primary health care clinics. Our results agree with those that were reported in a study of children and adolescences with depression, where researchers found that seropositivity to T. gondii was significantly higher in patients with suicidal ideation than in those without suicidal ideation [19]. In contrast, our results conflict with those that were reported in some studies. A negative association between seroprevalence of $T$. gondii infection and suicidal ideation was found in patients suffering from mental and behavioral disorders due to psychoactive substance use [20]. The difference in the association among the studies could be due to the difference in the characteristics of the populations studied. In the study of patients with mental and behavioral disorders, patients were treated, and this condition might have prevented suicidal ideation. In a National Health and Nutrition Survey of 5487 subjects that were aged 20 to 80 years in the USA, neither T. gondii seroprevalence nor anti-T. gondii antibody titer was positively associated with suicidal ideation [21]. The difference in the characteristics of the populations studied might explain the difference in the association among the studies. For instance, our study population consisted of outpatients attending primary care, whereas in the American study, people from the general population of the U.S. were studied. Regarding suicide attempts, no association between T. gondii infection and suicide attempts in general was found. However, stratification by age groups showed that $T$. gondii infection was associated with suicide attempts in individuals that were aged 31-50 years. No association between $T$. gondii seropositivity and suicide attempts was found in other studies, including psychiatric outpatients [16] and patients with recurrent mood disorders [15]. In contrast, a positive association between T. gondii seropositivity and suicide attempts has been found in women of postmenopausal age [22] and psychiatric patients [17]. In two recent meta-analyses, researchers confirmed that infection with $T$. gondii is a potential risk factor for suicidal behavior [23,24]. We did not find an association between high levels of anti-T. gondii IgG antibodies and suicidal ideation or suicide attempts in general. However, a borderline $(p=0.05)$ association between high antibody levels and suicidal ideation in individuals that were aged $\leq 30$ years was found. High levels of anti-T. gondii IgG antibodies have been associated with suicide attempts in patients with recurrent mood disorders [15], psychiatric outpatients [16], and patients with schizophrenia younger than 38 years [25]. Remarkably, we found an association between seropositivity to T. gondii and a high ( $>3)$ number of suicide attempts. This finding agrees with the one that was found in a study of psychiatric outpatients, where the rate of T. gondii seropositivity increased with the number of suicide attempts [16]. In contrast, in a study of patients with recurrent mood disorders, no significant relationship was found between T. gondii seropositivity and number of prior suicide attempts [15]. In the present study, we found a borderline $(p=0.05)$ association between seropositivity to anti-T. gondii IgM antibodies in the participants with anti-T. gondii IgG antibodies and suicide attempts. This finding suggests that a recent $T$. gondii infection could be associated with suicide attempts. If our findings are confirmed by further studies, then physicians providing primary care consultations might consider testing for T. gondii exposure of their patients with suicidal behavior and those with suicide risk factors, including, for instance, people with depression, anxiety, or with a family history of suicide attempts. 


\section{Materials and Methods}

Through a cross-sectional study design, we surveyed 2045 people attending primary health care clinics in Durango, Mexico, from 2014 to 2019. The inclusion criteria for enrollment in the survey were: (1) people attending primary health care clinics in Durango, Mexico; (2) any gender; (3) aged $\geq 15$ years; and, (4) with a written informed consent. Of the 2045 people that were enrolled in the survey, 1696 were women and 349 were men. The mean age of participants was $40.29 \pm 12.78$ (range 15-84) years.

In-person interviews were conducted for the survey data collection. Participants were asked about suicidal behavior, including a history of suicidal ideation, suicide attempts, number of suicide attempts, date of last suicide attempt, and the methods used for suicide attempt.

The participants provided a blood sample that was centrifuged, and the sera obtained was frozen at $-20^{\circ} \mathrm{C}$ until analyzed. All of the serum samples were analyzed for the detection of anti-T. gondii IgG antibodies using a commercially available enzyme immunoassay "Toxoplasma gondii IgG" kit (Diagnostic Automation/Cortez Diagnostics, Inc., Woodland Hills, CA. USA). Serum samples with the presence of anti-T. gondii IgG antibodies were further analyzed for the detection of anti-T. gondii IgM antibodies by a commercially available enzyme immunoassay "Toxoplasma gondii IgM" kit (Diagnostic Automation/Cortez Diagnostics, Inc.). All of the tests were performed following the instructions of the manufacturer. Positive and negative controls that were provided in the kits were included in each run. The serum samples were analyzed soon (no more than two months) after freezing.

Analysis of data was performed with the software IBM SPSS Statistics version 20 and Epi Info version 7. Sample size was calculated using the following values: a population size of 300000, an expected frequency of T. gondii exposure of $6.1 \%$ [26], confidence limits of $2 \%$, a design effect of 1 , and a confidence level of $99.9 \%$. A sample size of 1542 was obtained. The Fisher's exact test (for small values) and Pearson's chi-square test were used to compare the frequencies of seropositivity and serointensity among the groups. The association between variables was assessed by calculating the odd ratios (OR) and 95\% confidence intervals $(\mathrm{CI})$, and a $p$ value of less than 0.05 was considered to be statistically significant.

\section{Conclusions}

Our results indicate that $T$. gondii exposure is associated with suicidal behavior among people attending primary care clinics. Our findings further support the association between T. gondii infection and suicidal behavior that was reported in other population groups.

Author Contributions: Conceptualization, C.A.-E.; methodology, C.A.-E., S.E.-M., A.R.-N., A.R.P.Á., I.B.-G., S.M.C.-S., A.S.-Á., C.A.G.-A., and L.S.-S.; formal analysis, C.A.-E., Á.O.A.-F., G.A.A.F.; writing-original draft preparation, C.A.-E.; writing-review and editing, C.A.-E.; funding acquisition, C.A.-E. All authors have read and agreed to the published version of the manuscript.

Funding: This research was funded by Secretary of Public Education, Mexico (Grant No. DSA/103.5/14/11311).

Institutional Review Board Statement: The study was conducted according to the guidelines of the Declaration of Helsinki, and approved by the Institutional Review Board of Institute of Security and Social Services for State Workers, General Hospital of the Secretary of Health and Faculty of Medicine and Nutrition of the Juarez University of Durango State.

Informed Consent Statement: Informed consent was obtained from all subjects involved in the study.

Data Availability Statement: Data is provided within the article.

Conflicts of Interest: The authors declare no conflict of interest. The funders had no role in the design of the study; in the collection, analyses, or interpretation of data; in the writing of the manuscript, or in the decision to publish the results. 


\section{References}

1. Johnson, S.K.; Johnson, P.T.J. Toxoplasmosis: Recent Advances in Understanding the Link between Infection and Host Behavior. Annu. Rev. Anim. Biosci. 2021, 9, 249-264. [CrossRef] [PubMed]

2. Augusto, L.; Wek, R.C.; Sullivan, W.J., Jr. Host sensing and signal transduction during Toxoplasma stage conversion. Mol. Microbiol. 2020. [CrossRef]

3. Almeria, S.; Dubey, J.P. Foodborne transmission of Toxoplasma gondii infection in the last decade. An overview. Res. Vet. Sci. 2021, 135, 371-385. [CrossRef]

4. Dubey, J.P.; Cerqueira-Cézar, C.K.; Murata, F.H.A.; Kwok, O.C.H.; Yang, Y.R.; Su, C. All about toxoplasmosis in cats: The last decade. Vet. Parasitol. 2020, 283, 109145. [CrossRef]

5. Montoya, J.G.; Liesenfeld, O. Toxoplasmosis. Lancet 2004, 363, 1965-1976. [CrossRef]

6. Ortiz-Guerrero, G.; Gonzalez-Reyes, R.E.; de-la-Torre, A.; Medina-Rincón, G.; Nava-Mesa, M.O. Pathophysiological Mechanisms of Cognitive Impairment and Neurodegeneration by Toxoplasma gondii Infection. Brain Sci. 2020, 10, 369. [CrossRef]

7. Alvarado-Esquivel, C.; Sanchez-Anguiano, L.F.; Hernandez-Tinoco, J.; Berumen-Segovia, L.O.; Torres-Prieto, Y.E.; EstradaMartinez, S.; Perez-Alamos, A.R.; Ortiz-Jurado, M.N.; Molotla-de-Leon, G.; Beristain Garcia, I.; et al. Toxoplasma gondii Infection and Mixed Anxiety and Depressive Disorder: A Case-Control Seroprevalence Study in Durango, Mexico. J. Clin. Med. Res. 2016, 8, 519-523. [CrossRef]

8. Alvarado-Esquivel, C.; Urbina-Álvarez, J.D.; Estrada-Martínez, S.; Torres-Castorena, A.; Molotla-de-León, G.; Liesenfeld, O.; Dubey, J.P. Toxoplasma gondii infection and schizophrenia: A case control study in a low Toxoplasma seroprevalence Mexican population. Parasitol. Int. 2011, 60, 151-155. [CrossRef]

9. Kezai, A.M.; Lecoeur, C.; Hot, D.; Bounechada, M.; Alouani, M.L.; Marion, S. Association between schizophrenia and Toxoplasma gondii infection in Algeria. Psychiatry Res. 2020, 291, 113293. [CrossRef]

10. Stepanova, E.V.; Kondrashin, A.V.; Sergiev, V.P.; Morozova, L.F.; Turbabina, N.A.; Maksimova, M.S.; Romanov, D.V.; Kinkulkina, M.A.; Lazareva, A.V.; Morozov, E.N. Toxoplasmosis and mental disorders in the Russian Federation (with special reference to schizophrenia). PLoS ONE 2019, 14, e0219454. [CrossRef]

11. Miman, O.; Mutlu, E.A.; Ozcan, O.; Atambay, M.; Karlidag, R.; Unal, S. Is there any role of Toxoplasma gondii in the etiology of obsessive-compulsive disorder? Psychiatry Res. 2010, 77, 263-265. [CrossRef]

12. Sutterland, A.L.; Fond, G.; Kuin, A.; Koeter, M.W.; Lutter, R.; van Gool, T.; Yolken, R.; Szoke, A.; Leboyer, M.; de Haan, L. Beyond the association. Toxoplasma gondii in schizophrenia, bipolar disorder, and addiction: Systematic review and meta-analysis. Acta Psychiatr. Scand. 2015, 132, 161-179. [CrossRef]

13. Flegr, J.; Havlícek, J.; Kodym, P.; Malý, M.; Smahel, Z. Increased risk of traffic accidents in subjects with latent toxoplasmosis: A retrospective case-control study. BMC Infect. Dis. 2002, 2, 11. [CrossRef]

14. Samojłowicz, D.; Borowska-Solonynko, A.; Kruczyk, M. New, previously unreported correlations between latent Toxoplasma gondii infection and excessive ethanol consumption. Forensic. Sci. Int. 2017, 280, 49-54. [CrossRef]

15. Arling, T.A.; Yolken, R.H.; Lapidus, M.; Langenberg, P.; Dickerson, F.B.; Zimmerman, S.A.; Balis, T.; Cabassa, J.A.; Scrandis, D.A.; Tonelli, L.H.; et al. Toxoplasma gondii antibody titers and history of suicide attempts in patients with recurrent mood disorders. J. Nerv. Ment. Dis. 2009, 197, 905-908. [CrossRef]

16. Alvarado-Esquivel, C.; Sánchez-Anguiano, L.F.; Arnaud-Gil, C.A.; López-Longoria, J.C.; Molina-Espinoza, L.F.; Estrada-Martínez, S.; Liesenfeld, O.; Hernández-Tinoco, J.; Sifuentes-Álvarez, A.; Salas-Martínez, C. Toxoplasma gondii infection and suicide attempts: A case-control study in psychiatric outpatients. J. Nerv. Ment. Dis. 2013, 201, 948-952. [CrossRef] [PubMed]

17. Bak, J.; Shim, S.H.; Kwon, Y.J.; Lee, H.Y.; Kim, J.S.; Yoon, H.; Lee, Y.J. The Association between Suicide Attempts and Toxoplasma gondii Infection. Clin. Psychopharmacol. Neurosci. 2018, 16, 95-102. [CrossRef]

18. Melhem, N.M.; Brent, D. Do Brief Preventive Interventions for Patients at Suicide Risk Work? JAMA Psychiatry 2020, 77, 997-999. [CrossRef]

19. Yalın Sapmaz, Ş.; Şen, S.; Özkan, Y.; Kandemir, H. Relationship between Toxoplasma gondii seropositivity and depression in children and adolescents. Psychiatry Res. 2019, 278, 263-267. [CrossRef]

20. Alvarado-Esquivel, C.; Carrillo-Oropeza, D.; Pacheco-Vega, S.J.; Hernández-Tinoco, J.; Salcedo-Jaquez, M.; Sánchez-Anguiano, L.F.; Ortiz-Jurado, M.N.; Alarcón-Alvarado, Y.; Liesenfeld, O.; Beristain-García, I. Toxoplasma gondii exposure in patients suffering from mental and behavioral disorders due to psychoactive substance use. BMC Infect. Dis. 2015, 15, 172. [CrossRef]

21. Gale, S.D.; Berrett, A.N.; Brown, B.; Erickson, L.D.; Hedges, D.W. No association between current depression and latent toxoplasmosis in adults. Folia Parasitol. 2016, 63. [CrossRef]

22. Ling, V.J.; Lester, D.; Mortensen, P.B.; Langenberg, P.W.; Postolache, T.T. Toxoplasma gondii seropositivity and suicide rates in women. J. Nerv. Ment. Dis. 2011, 199, 440-444. [CrossRef]

23. Soleymani, E.; Faizi, F.; Heidarimoghadam, R.; Davoodi, L.; Mohammadi, Y. Association of T. gondii infection with suicide: A systematic review and meta-analysis. BMC Public Health 2020, 20, 1-7. [CrossRef]

24. Amouei, A.; Moosazadeh, M.; Nayeri Chegeni, T.; Sarvi, S.; Mizani, A.; Pourasghar, M.; Hosseini Teshnizi, S.; Hosseininejad, Z.; Dodangeh, S.; Pagheh, A.; et al. Evolutionary puzzle of Toxoplasma gondii with suicidal ideation and suicide attempts: An updated systematic review and meta-analysis. Transbound. Emerg. Dis. 2020, 67, 1847-1860. [CrossRef] 
25. Okusaga, O.; Langenberg, P.; Sleemi, A.; Vaswani, D.; Giegling, I.; Hartmann, A.M.; Konte, B.; Friedl, M.; Groer, M.W.; Yolken, R.H.; et al. Toxoplasma gondii antibody titers and history of suicide attempts in patients with schizophrenia. Schizophr. Res. 2011, 133, 150-155. [CrossRef]

26. Alvarado-Esquivel, C.; Estrada-Martínez, S.; Pizarro-Villalobos, H.; Arce-Quiñones, M.; Liesenfeld, O.; Dubey, J.P. Seroepidemiology of Toxoplasma gondii infection in general population in a northern Mexican city. J. Parasitol. 2011, 97, 40-43. [CrossRef] 